\title{
REGULATION OF DYNAMIXEL ACTUATORS IN ROBOT MANIPULATOR MOVEMENT
}

\author{
Marek VACEK, Jaroslava ŽILKOVÁ, Marek PÁSTOR \\ Department of Electrical Engineering and Mechatronics, Faculty of Electrical Engineering and Informatics, \\ Technical University of Košice, Letná 9, 04200 Košice, tel. 055/602 2155, e-mail: \{marek.vacek, jaroslava.zilkova, \\ marek.pastor\}@tuke.sk
}

\begin{abstract}
The article deals with the possibilities of movement control of a five-joint robot manipulator, which is composed of Dynamixel actuators. It contains a description of sending user-defined data, which are stored in individual addresses of the actuators' control unit. According to these data, the actuator is able to change the parameters of movement, such as velocity, dynamics of acceleration and deceleration, accuracy of reaching a specific position, etc. The article also compares the settings of individual parameters.
\end{abstract}

Keywords: dynamixel, SDK, robot manipulator, actuator

\section{INTRODUCTION}

Dynamixel is a high-performance system developed by the Robotis company, designed for robotic applications, and controlled via digital packets. The system is composed of the actuator itself (a DC motor), a built-in gearbox, various parameter sensors, and a control unit, which enables communication between the Dynamixel system and the PC (via a communication unit).

The advantages of this system include immediate feedback about reaching the desired position, overloading, or overheating, as well as the possibility of further communication between the actuators - they are linked in series. The control program includes a definition of which parameter is attributed to which actuator. The signal is then transmitted from motor to motor (direction of communication - first motor - second motor - third motor etc.), with the program's request being carried out only on the chosen actuator (defining the motor's ID) [1].

\section{ACTUATOR CONTROL}

Actuator control is carried out by loading and storing data into the control table. These data are saved in predefined addresses in the actuator's memory. The data stay in the memory while the actuator is connected to the supply voltage. From among more than fifty available settings, these can be given as an example:

0x1E - goal angular position lower byte

$0 \times 1 F$ - goal angular position upper byte

0x20 - goal moving speed lower byte

0x21 - goal moving speed upper byte

0x28 - present load lower byte

0x29 - present load upper byte

$0 \times 2 \mathrm{~A}$ - present voltage

$0 \times 2 \mathrm{~B}$ - present temperature

All types of Dynamixel actuators use the same configuration addresses. An important difference between the actuator series (AX and MX) used in the controlled robot manipulator are the settings of their dynamic properties.

For the MX actuator series, the setting of the required dynamics is defined via the PID rotation controller; the addresses in the memory are as follows:

$0 \times 1 \mathrm{~A}$ - derivative gain

$0 \times 1 \mathrm{~B}$ - integral gain

$0 \times 1 C$ - proportional gain

For the AX actuator series, the parameters in Fig. 1 are set in the RAM.

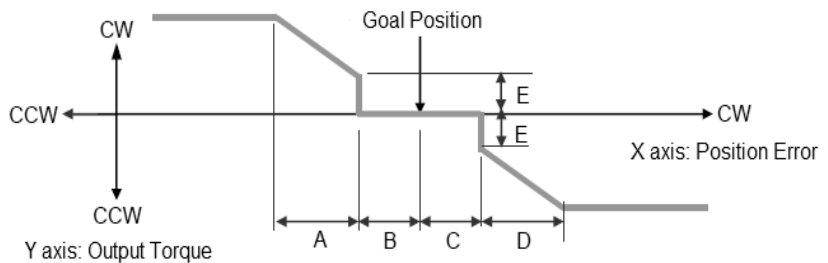

Fig. 1 Setting of the dynamics of the AX actuators [1]
A: CCW compliance slope (address 0x1D)
$\mathrm{B}$ : CCW compliance margin (address $0 \times 1 \mathrm{~B}$ )
$\mathrm{C}$ : $\mathrm{CW}$ compliance margin (address $0 \mathrm{x} 1 \mathrm{~A}$ )
D: CW compliance slope (address 0x1C)
E: punch (address 0x30, 0x31)
$\mathrm{CW}$ - clockwise
$\mathrm{CCW}$ - counterclockwise

All actuator parameters are changed in the Dynamixel Software Development Kit (SDK), which also enables communication control between the Dynamixel actuators and the computer. The library includes the commands to, for example:

- establish communication

- $\quad$ set the communication speed

- define the serial port

- verify successful communication

- store the required variables in the defined addresses 
Table 1 Description of the robot manipulator [2]

$\begin{array}{ccccccc}\text { Joint } & \text { Actuator } & \text { Range } & \text { d } & \text { a } & \boldsymbol{\alpha} & \boldsymbol{\theta} \\ \mathbf{1} & \text { MX-28T } & -174^{\circ} \text { to } 186^{\circ} & 136,9 \mathrm{~mm} & 0 \mathrm{~mm} & -90^{\circ} & 0^{\circ} \\ \mathbf{2} & \text { MX-64T } & -90^{\circ} \text { to } 90^{\circ} & 0 \mathrm{~mm} & 201,8 \mathrm{~mm} & 0^{\circ} & 0^{\circ} \\ \mathbf{3} & \text { MX-64T } & 0^{\circ} \text { to } 180^{\circ} & 0 \mathrm{~mm} & 200 \mathrm{~mm} & -90^{\circ} & 0^{\circ} \\ \mathbf{4} & \text { AX-12A } & -150^{\circ} \text { to } 150^{\circ} & 0 \mathrm{~mm} & 18,5 \mathrm{~mm} & 0^{\circ} & 0^{\circ} \\ \mathbf{5} & \text { AX-12A } & 0^{\circ} \text { to } 180^{\circ} & 80,9 \mathrm{~mm} & 0 \mathrm{~mm} & 0^{\circ} & 0^{\circ}\end{array}$

\section{ROBOT MANIPULATOR}

From the very beginning, when the robot manipulator was being designed, it was determined that Dynamixel actuators by Robotis would be used [2]. These are the most suitable for the application in question because all of the elements of the system - DC motor, gearbox, and the control unit (single-chip microprocessor) - are placed inside the actuator casing. They can communicate with the computer (MATLAB, LabView, etc.) either via a separate control unit (CM-5, CM-1), or, as in this case, via a USB2Dynamixel communication unit - communication via TTL.

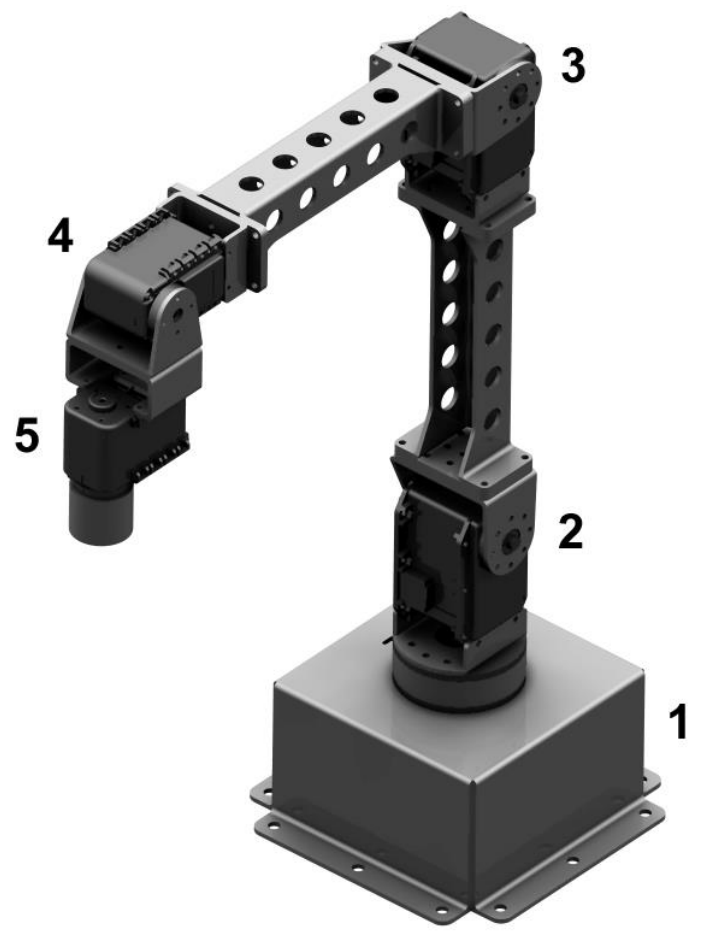

Fig. 2 Used Seriallink Robot Manipulator. Numbers in the picture are IDs of each actuator (first one is located inside the base) [2]

The designed robot manipulator is composed of five Dynamixel actuators. Placing and dimensions of individual actuators can be described by DenavitHartenberg parameters, which are given in Table 1, along with the types of actuators for individual joints and with the rotation range of individual robot manipulator joints. Given rotation ranges take into account the physical possibilities of the joints and the rotation range of individual actuators. The Denavit-Hartenberg parameter $\theta$ represents a variable which describes the rotation of the joints. $\theta=0$ is the robot's initial position, to which limits on rotation apply $[3,4]$.

Three types of actuators were used in this design, according to the different load of different parts of the arm (Fig. 2):

- joint 1 - MX-28T (metal gearbox, gear reduction 193:1, maximum torque $2.5 \mathrm{Nm}$ );

- joints 2 and 3 - MX-64T (metal gearbox, gear reduction 200:1, maximum torque $6 \mathrm{Nm}$ ).

- due to low load and low price, the rest of the joints (4 and 5) use AX-12A actuators (plastic gearbox, gear reduction $254: 1$, maximum torque $1.5 \mathrm{Nm}$ )

For the robot manipulator to run precisely and smoothly, it is necessary to set the correct values of the actuators' dynamic parameters. When choosing the individual actuators, it is appropriate to take into account the purchase price, the construction, and to consider the actuators' durability when used frequently [2].

\section{REGULATION OF INDIVIDUAL ACTUATORS}

\subsection{Settings of the dynamic parameters of the $\mathrm{AX}$ series actuators}

Fig. 1 shows the description of the individual parameters influencing the dynamics of the actuators. As can be seen, the actuator's torque is directly dependent on the actuator's position deviation. Since it was necessary to apply the required torque regulation on both rotation directions equally, the $\mathrm{CW}$ compliance slope and the CCW compliance slope parameters were set to the same values. The $\mathrm{CW}$ compliance margin and the $\mathrm{CCW}$ compliance margin parameters were set to the minimum value 1 to achieve the most exact rotation of the actuator.

Fig. 3 shows the progress of the actuator rotation in time, the required value of rotation being changed for different settings of the $\mathrm{CW}$ compliance slope parameter. The measurement was carried out on an unloaded actuator without additional moment of inertia, with $50 \%$ of the maximum angular velocity.

The course of rotation with increased moment of inertia and with $50 \%$ of the maximum angular velocity is shown in Fig. 4. 


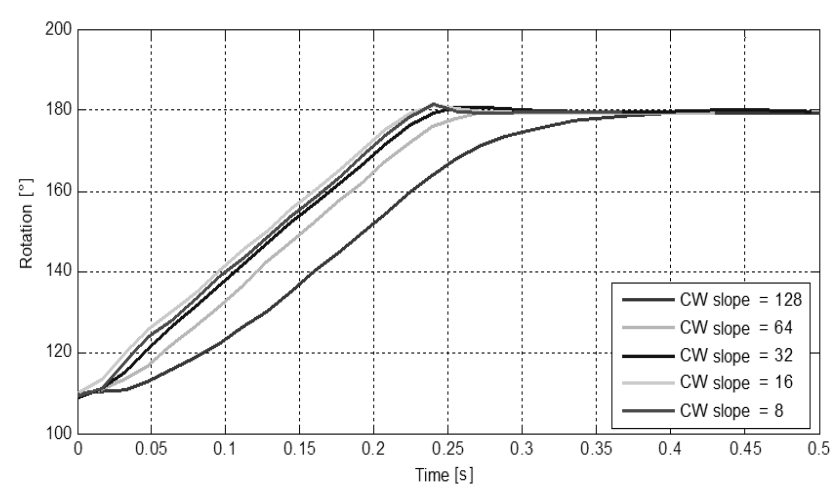

Fig. 3 The AX series actuator dynamics settings (without additional moment of inertia)

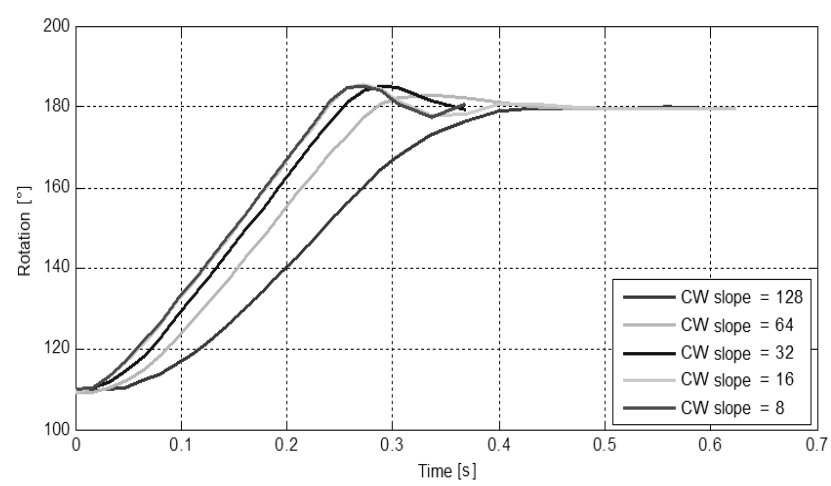

Fig. 4 The AX series actuator dynamics settings (increased moment of inertia)

The last measurement was carried out on the robotic manipulator's fourth joint. The initial position was set to 0 , and the manipulator was supposed to turn by $90^{\circ}$, stay in the required position, and return to the initial position (Fig. 5).

The measurements show that it is appropriate to set the $\mathrm{CW}$ compliance slope to 128 because there is no overshoot when reaching the desired position. This way, smooth movement of the robot manipulator was achieved. The main disadvantage of this setting is the inability to reach the exact desired position, which follows from Fig. 1.

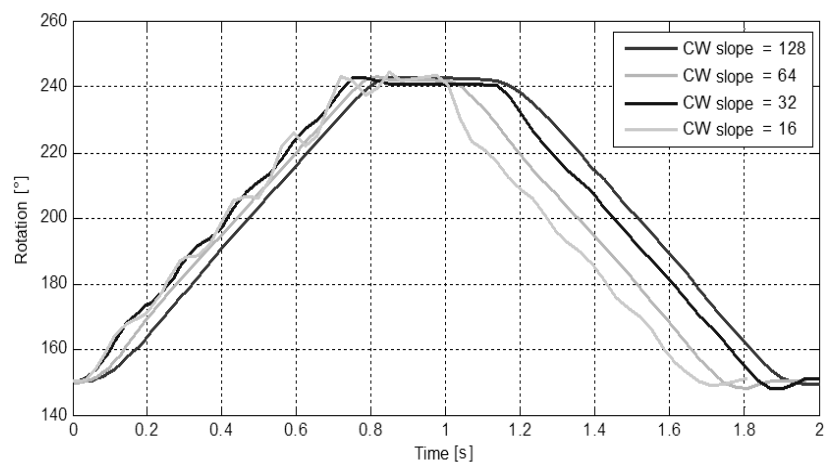

Fig. 5 The AX series actuator dynamics settings (measurement on the robot manipulator's fourth joint)
Taking into consideration the margin and the durability of actuator gearboxes, this setting is the most advantageous.

\subsection{Settings of the dynamic parameters of the MX series actuators}

The MX series actuators use a PID controller to control the required position. This way, the main disadvantage of the AX series actuators - not reaching the required position - is disposed of. The PID controller is composed of a proportional, integral, and derivative component. During our measurement, only the setting of the proportional and integral gain was changed. The derivative gain was set to zero. The size of the proportional component can be determined based on Table 2 , which expresses the relation between the set value of slope and the setting of the proportional controller gain.

Table 2 Comparison of the slope settings with the setting of the proportional component of the PID controller [1]

$\begin{array}{cc}\text { Slope } & \text { P-gain } \\ 8 & 128 \\ 16 & 64 \\ 32 & 32 \\ 64 & 16 \\ 128 & 8\end{array}$

When the proportional controller gain is set to 8 , the dynamics of the MX series actuators becomes similar to those of the AX series. Further setting of the integral gain can compensate for the deviation in the rotation of the actuator under sustained load.

The measurements were carried out on the robot manipulator's second joint, similarly to the previous measurement. The values of gain of the controller's integral component were measured (Fig. 6).

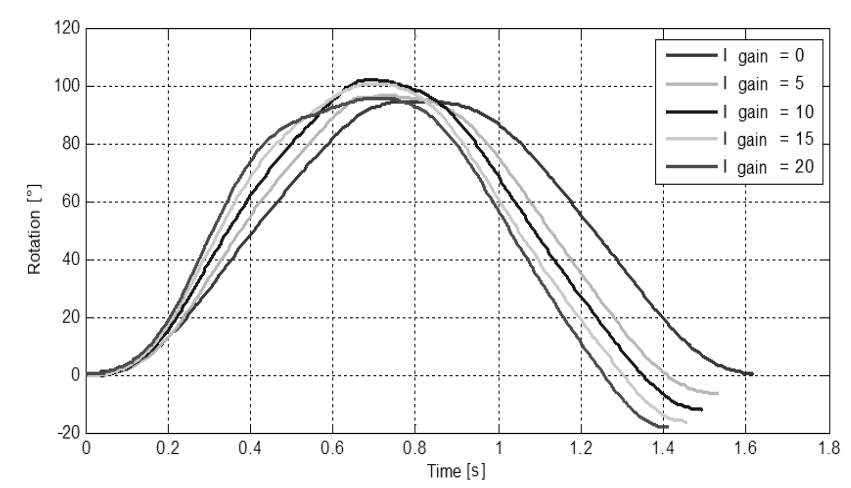

Fig. 6 The impact of the controller's integral component

Generally, the higher the integral gain, the greater are the dynamics of the actuator and the speed of control deviation regulation. If the value of gain is set too high, there is no overshoot. 


\section{CONCLUSIONS}

This article is concerned with the possibilities of movement control of a five-joint robot manipulator, which is composed of Dynamixel actuators (the AX and MX series). All control commands are sent to the actuators using predefined addresses, which are the same for all series. The main differences between the AX and MX series are in the type of construction and in the control unit. While the movement parameters of an $\mathrm{AX}$ actuator are defined only as the value of $\mathrm{CW}$ and $\mathrm{CCW}$ compliance slope and margin, the MX series uses a full PID controller. Using this controller, it is possible to achieve more exact values of robot manipulator joint rotation into the user-defined position.

Fig. 7 shows a comparison of the required value of rotation of four actuators with the measured values (since the fifth actuator rotates only the robot manipulator's effector, it was not included in the measurements). It can be seen that the robot manipulator slightly lags behind the required values. If the actuator is under bigger load (its torque is more than $70 \%$ ), it is able to reach the required rotation, albeit with a small deviation (approximately $\left.1.5^{\circ}\right)$.

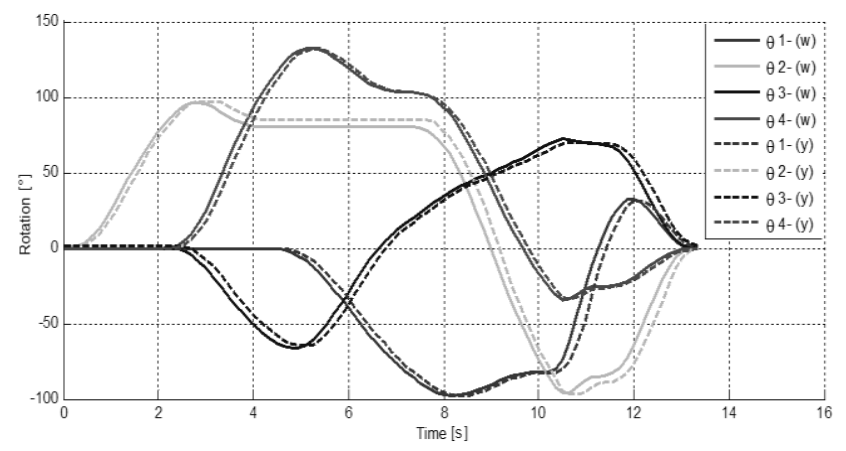

Fig. 7 Comparison of the required rotation of the actuators (w) with the actual $(y)$

\section{ACKNOWLEDGMENT}

Published with the support of project KEGA 011TUKE-4/2013.

This work was supported by the Slovak Research and Development Agency under the contract No. APVV0185-10.

\section{REFERENCES} $\begin{array}{lrr}\text { [1] Robotis } & \text { Dynamixel } \\ \text { Avaliable } & \text { on } & \begin{array}{c}\text { Documentation } \\ \text { the }\end{array}\end{array}$ <http://support.robotis.com/en/>.

[2] VACEK, M.: Optical safety system for robotic workplace - "Optický bezpečnostný systém robotického pracoviska", Technical university of Košice, Faculty of Electrical Engineering and Informatics, Postgraduate Thesis, 2013.
[3] REZA N. JAZAR: Theory of Applied Robotics. Springer New York Dordrecht Heidelberg London 2007.893 s. ISBN 978-1-4419-1749-2.

[4] CORKE, P.: Robotics, Vision and Control. SpringerVerlag Berlin Heidelberg 2011. 570 s. ISBN 978-3642-20143-1.

[5] CORKE, P.: Robotics Toolbox for MATLAB, Release 9. Available on the Internet: <http://www.petercorke.com/RTB/robot.pdf>.

[6] MATHWORKS MATLAB: R2012a Documentation [online]. Available on the Internet: <http://www.mathworks.com/help/techdoc/>.

[7] PAGÉS, J. - COLLEWET, CH.: A camera-projector system for robot positioning by visual servoing, University of Girona, Institut d'Inform 'atica i Aplicacions, Girona, 2006.

[8] KULIĆ, D.: Safety for Human-Robot Interaction, The University of British Columbia, Vancouver, 2005.

[9] OGORODNIKOVA, O.: Human Robot Interaction: Safety Challenge, Budapest University of Technology andd Economics, Budapest, 2010.

[10] SIVÝ, R.: Ovládanie servopohonov robota Bioloid, Technická univerzita v Košiciach, Fakulta Elektrotechniky a informatiky, 2012.

Received September 11, 2014 , accepted October 17, 2014

\section{BIOGRAPHIES}

Marek Vacek (Ing.) was born in Liptovský Mikuláš (Slovakia) in 1986. He graduated from the Department of Electrical Engineering and Mechatronics at FEI TU of Košice. He now works on getting his $\mathrm{PhD}$ at the same department at FEI TU of Košice. His research interests include robotics, artificial intelligence and camera systems.

Jaroslava Žilková (Doc., Ing., PhD.) received the MSc. Degree at the Technical University of Košice, at the Department of Technical Cybernetics of the FEI. She finished her $\mathrm{PhD}$. Thesis, which dealt with estimation of induction motor variables based on artificial neural networks, in 2001 at the Department of Electrical Drives of the Faculty of Electrical Engineering and informatics at the same university. Since 2008 she has been an associative professor at the Department of electrical Drives of the FEI TU Košice. Her field of interest is mathematical modelling and application of modern control methods to electrical drives, state estimation of AC using neural networks.

Marek Pástor (Ing.) was born in Košice (Slovakia) in 1985. He received his master degree in electrical engineering in 2010. He is currently working towards a $\mathrm{PhD}$. degree at Dept. of Electrical Engineering and Mechatronics, Technical University of Košice, Slovakia. His interest is in the area of power electronics. 